\title{
A Experiência do Estágio Docente de Licenciatura de Computação no IFPE/Garanhuns
}

\author{
Marcos U. Felix de Farias', José Andersson S. da Silva², Hérikles Vinícyus F. \\ Cordeiro $^{3}$, Anselmo L. Gomes ${ }^{4}$, Sônia R. Fortes da Silva ${ }^{5}$ \\ ${ }^{1}$ Universidade de Pernambuco, Campus Garanhuns (UPE) \\ CEP 55.294-902 - Garanhuns - PE - Brasil \\ \{uryel.farias, anderssonsoares97, heriklescordeiro\}@gmail.com \\ anselmo.gomes@upe.br, fortes.sonia@gmail.com
}

\begin{abstract}
This article reports on the experience of undergraduates in Computing at the University of Pernambuco, Multi Campi Garanhuns, during the course of Supervised Internship I, that was held at the Institute of Education, Science and Technology of Pernambuco, Campus Garanhuns. It describes the activities carried out in the classroom by the authors who acted as teachers in the school context of an educational institution, which is recognized for its contribution to the professional technical modality of this country. It was verified that the Supervised Internship is an interinstitutional relationship that provokes in the teacher in training the professional, pedagogical and political experience of the teaching-learning action.
\end{abstract}

Resumo. Este artigo relata a experiência, vivenciada pelos licenciandos em Computação da Universidade de Pernambuco, Multicampi Garanhuns, durante a disciplina de Estágio Supervisionado I, realizada no Instituto Federal de Educação, Ciência e Tecnologia de Pernambuco, Campus Garanhuns. Descreve as atividades realizadas em sala de aula por estes autores que atuaram como professores no âmbito escolar de uma instituição de ensino, reconhecida pela sua contribuição à modalidade profissional técnica deste país. Constatou-se que o Estágio Supervisionado é uma relação interinstitucional que provoca no docente em formação a experiência profissional, pedagógica e política da ação de ensino-aprendizagem.

\section{Introdução}

A educação escolar, em todos os níveis, geralmente esteve restrita a lugares e tempos determinados, como: salas de aula, calendário escolar, matriz curricular, modelos pedagógicos centrados no professor ou no educando, que procuravam apoiar o ensinoaprendizagem, de modo que cada indivíduo conseguisse avançar no processo de apreender. Além disto, encontra limites do conteúdo programático, do tempo de aula,

\footnotetext{
${ }^{1}$ Estudante do curso de Licenciatura em Computação da UPE e bolsista do Programa Institucional de Bolsas de Iniciação a Docência (PIBID).

2 Estudante do curso de Licenciatura em Computação da UPE e bolsista do Programa Institucional de Bolsas de Iniciação a Docência (PIBID).

${ }^{3}$ Estudante do curso de Licenciatura em Computação da UPE.

${ }^{4}$ Mestre em Ciência da Computação e Prof. Substituto do IFPE.

5 Mestra e Doutora em Educação e Prof. Titular da UPE.
}

DOI: $10.5753 /$ cbie.wcbie. 2017.853 
das normas legais, e, por conta deste contexto, boa parte dos professores se torna previsível, não surpreende os educandos e repete fórmulas e sínteses (MORAN, 2003).

No atual contexto educacional, o Estágio obrigatório é considerado um dos principais pontos da formação a ser discutido durante o processo de aprendizagem da carreira profissional de um professor. No Estágio do trabalho docente se tem contato com o ambiente escolar, com o educando, com o que e como se ensina e aprende, tendo a percepção da dimensão da docência. O Estágio é um componente curricular na formação profissional, tendo como ponto central a tentativa de articulação entre teoria e prática, caracterizando-se como parte importante das relações entre escola e universidade, teoria - prática, formando um verdadeiro elo de articulação entre estes e a própria realidade. Constitui-se um campo de conhecimento, o que "significa atribuir-lhe um estatuto epistemológico que supere sua tradicional redução à atividade prática instrumental" (PIMENTA \& LIMA, 2011, p. 29).

Nesse contexto, o presente artigo relata a experiência de um grupo de discentes do Curso de Licenciatura em Computação da Universidade de Pernambuco - UPE, Multicampi Garanhuns, que através do projeto de Estágio Supervisionado, atuaram como docentes no Instituto Federal de Educação, Ciência e Tecnologia de Pernambuco (IFPE), do campus Garanhuns, por meio das atividades de Ensino e Extensão. As atividades do Estágio Supervisionado foram subdivididas nestas duas dimensões, cada uma contendo um objetivo específico a ser alcançado, mas integradas nas atividades da docência.

\section{Estágio em Licenciatura em Computação}

De acordo com Kulcsar (2012) os estágios supervisionados são considerados uma parte importante da relação trabalho-escola e da teoria e prática. É através dessa prática que os discentes de Licenciatura em Computação entram em contato com a realidade de um ambiente de ensino e de aprendizagem. Desta forma, os discentes do curso de Licenciatura em Computação, por meio do estágio, conhecem a realidade das escolas, suas condições de trabalho e seu projeto pedagógico.

Scaico et al. (2012) relatam uma experiência de estagiários de Licenciatura em Ciência da Computação com atividades que estimularam o pensamento computacional em turmas do Ensino Fundamental. Diferente de outros trabalhos, pois os discentes analisaram pontos falhos em uma atividade que se propunha a trabalhar o tema "Representação da Informação" e a modificaram, assim melhorando-a. Adicionalmente, foram analisadas como diferentes turmas recebiam os mesmos estímulos, sendo possível entender, a partir de que ano escolar as crianças estavam aptas a receber as informações sobre aquele tema.

No entanto, o Estágio não deve se limitar à simples transferência e aplicação de teorias ou de conteúdos, de experiências vivenciadas por um grupo, como se aquilo ocorresse da mesma forma em outro contexto, mas à produção do conhecimento articulado entre os conteúdos da formação e o conhecimento da realidade da sala de aula da educação básica, seja em qualquer etapa ou modalidade. A experiência possibilita reformular saberes já aprendidos, reavaliando seus limites e possibilidades para a atuação profissional que se exige no tempo presente.

Assim, o discente é exigido a reconstruir a consciência que a análise de sua prática envolve um comportamento de observação, reflexão crítica e reorganização de 
suas ações, como indicador de desempenho profissional e de sua contribuição para as melhorias na educação. Considera-se também que a prática reflete o grau de aquisição teórica obtido na formação inicial, que vai contribuir para a sua própria identidade de mestre.

Além disto, a construção do conhecimento de um indivíduo pode ocorrer tanto pela sua relação com o meio em que está inserido ou com um objeto, como também na relação do indivíduo em colaboração com outros, assim como é dito na declaração a seguir:

\begin{abstract}
A interação entre o parceiro sentado ao lado, entre o computador, os conhecimentos, os professores que seguem o percurso da construção do conhecimento, e até mesmo os outros colegas que, apesar de estarem envolvidos com sua procura, pesquisa, navegação, prestam atenção ao que acontece em sua volta, gera uma grande equipe que busca a produção do conhecimento constantemente. (ROSÁRIO 2011, p. 14).
\end{abstract}

Assim, para Kulcsar (2012), o professor em formação ao longo da vida é o sujeito que tem a função de educador, a qual incorpora e ultrapassa as dimensões técnicas de seu trabalho e o âmbito da escola. Neste sentido, a docência é complexa em sua ligação com a educação e em sua referência à realidade sociopolítica da cultura.

\title{
3. Planejamento
}

As estratégias foram pensadas na forma de projeto de Estágio no IFPE, após encontro com a gestão, apresentando a Instituição, suas regras e suas necessidades emergentes para os educandos do curso técnico, a fim de que o processo de ensino e aprendizagem ocorresse de forma natural na sala de aula, com uma abordagem dinâmica pensada para ser utilizada na forma de ensinar.

O método de ensino baseou-se na aprendizagem colaborativa para resolução de problemas, elaborando as atividades práticas de forma que acontecessem no Ensino e na Extensão com a integração de educandos em conjunto com outros colegas. Nos exercícios era permitido, até certo nível, discutir a resolução e propor soluções. Mas, para chegar a esse ponto, o educando deveria se esforçar para solucionar as atividades e caso não conseguisse, poderia tanto recorrer aos discentes, como também, a algum colega, sob a nossa supervisão.

Diante dos argumentos expostos e da visão de elaborar um planejamento competente, foi proposta uma linha de raciocínio que levasse em consideração qual era o nível de conhecimento prévio dos educandos a respeito do conteúdo que seria abordado, como seria a mediação desse conteúdo para o educando e de que forma poderíamos conferir o desenvolvimento deste no decorrer do projeto. Tal proposta pode ser observada na Figura 1.

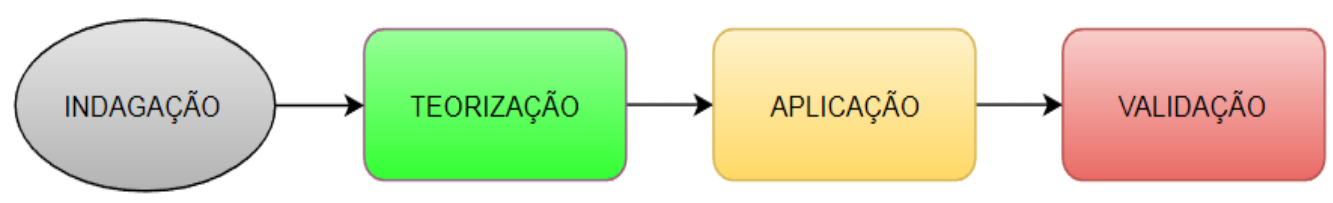

Figura 1. Fluxograma apresentando as etapas do projeto.

A imagem da Figura 1 demonstra o fluxograma que atua como etapas interrelacionadas presentes nos projetos de Ensino e Extensão, no qual o 
VI Congresso Brasileiro de Informática na Educação (CBIE 2017)

Anais dos Workshops do VI Congresso Brasileiro de Informática na Educação (WCBIE 2017)

questionamento/indagação é a etapa inicial de cada projeto, parte do planejamento, pois é imprescindível realizá-lo para que se delimite o problema e determine o que é importante ou não na coleta de dados sobre o tema que será abordado com os educandos na ação docente.

A próxima etapa, a teorização, foi o levantamento do conteúdo proposto pelos professores e pelo coordenador do curso de Informática do IFPE, como as áreas de maior dificuldade dos educandos, sendo estes: informática básica e programação orientada a objetos.

A fim de entrar na prática dos conteúdos que foram lecionados previamente na teorização, a terceira etapa denominada aplicação, teve a função de fazer com que os educandos (re)construíssem conhecimento por meio dos exercícios propostos durante as aulas. Foi pensando nestas etapas, que se chegou à última etapa do fluxograma, a qual teve o propósito de avaliar o conhecimento adquirido pelos educandos sobre os conteúdos abordados na aula.

Por meio das quatro etapas do fluxograma, base para o Ensino e a Extensão, foi implementado o estágio. Os conteúdos abordados no Ensino e na Extensão estão apresentados na Tabela 1, com os assuntos sugeridos pelos professores do IFPE, para serem empregados nas atividades do Estágio Supervisionado I.

\begin{tabular}{|c|c|}
\hline Dimensão & Atividades \\
\hline Ensino & $\begin{array}{l}\text { Aulas teóricas e práticas para os alunos da disciplina de Sistemas } \\
\text { Operacionais (SO). } \\
\text { Teve como conteúdo proposto pelo professor regente da disciplina: } \\
\text { - Comandos no Prompt de comando do sistema operacional } \\
\text { Windows (Cmd). } \\
\text { - Comandos do Terminal do sistema operacional Linux. }\end{array}$ \\
\hline \multirow[t]{2}{*}{ Extensão } & $\begin{array}{l}\text { Aulas de reforço sobre a linguagem de programação JAVA para os } \\
\text { alunos das disciplinas de Algoritmos e Lógica de Programação } \\
\text { Orientada a Objetos e Estruturas de Dados (LPOOED). Entre os } \\
\text { conteúdos indicados a serem lecionados no reforço estão: } \\
\text { - Tipos primitivos e manipulação de dados } \\
\text { - Operadores aritméticos e lógicos } \\
\text { - Estruturas condicionais e de repetição }\end{array}$ \\
\hline & $\begin{array}{l}\text { Apresentação de uma palestra intitulada, "A Importância da TI Verde } \\
\text { nas Empresas", que ocorreu no evento da semana do Meio Ambiente } \\
\text { (SMA) no IFPE. }\end{array}$ \\
\hline
\end{tabular}

Tabela 1. Descrição dos conteúdos abordados no Ensino e Extensão.

$\mathrm{Na}$ dimensão de Ensino foram ministradas quatro aulas abordando os conteúdos descritos na Tabela 1, para os alunos de duas turmas do $2^{\circ}$ ano na modalidade 
subsequente do curso de Técnico em Informática do IFPE, sendo para uma turma as aulas ocorriam no turno da manhã e para a outra no turno da tarde.

As aulas também contaram com a observação e avaliação do professor titular da disciplina de SO, sendo o discente avaliado por meio de um Barema, utilizado em prova didática de concurso público para docência, adaptado para as atividades da disciplina de Estágio Supervisionado I, preenchido pelo próprio professor titular da disciplina.

Já em Extensão foram ministradas aulas de reforço, visto que muitos educandos apresentavam dificuldades em disciplinas específicas de Computação, especificamente nas disciplinas de Algoritmo e LPOOED, além da palestra "A Importância da TI Verde nas Empresas", na Semana do Meio Ambiente (SMA) no IFPE.

A ideia para realização da palestra surgiu devido ao evento SMA que ocorre todos os anos no mês de junho no IFPE Campus Garanhuns, onde a coordenadora do evento SMA participou da nossa reunião com os coordenadores e professores do curso de Informática da instituição.

A coordenadora do SMA concedeu a liberdade para que nós pudéssemos escolher um assunto de Computação que se relacionasse com a temática de Meio Ambiente, desta forma após algumas discussões sugerimos o tema TI Verde, que seria apresentado no formato de uma palestra para os alunos, o que foi muito bem aceito tanto pela coordenadora quanto pelos demais integrantes da comissão do evento.

\section{Resultados da experiência no ensino de Computação}

Para cada dimensão do projeto de Estágio Supervisionado I considerando as suas diferentes metodologias e temas a serem explorados foram obtidos resultados que atingiram as nossas expectativas, sendo que até uma dessas dimensões obteve destaque pelo que foi apresentado.

Todas as etapas, incluindo o planejamento e execução, serão descritos nos tópicos a seguir, onde será descrito como foi toda a experiência de trabalho e seus respectivos resultados durante o ensino de Computação no Ensino, Extensão e Pesquisa.

\subsection{Ensino}

A partir do momento em que foi definido que as regências seriam ministradas na disciplina de Sistemas Operacionais, nós entramos em contato com o professor titular desta disciplina no IFPE, para assim determinarmos as turmas e os horários disponíveis para que pudéssemos ministrar as regências do Ensino.

Deste modo, após serem definidos as turmas e os horários, o professor titular da disciplina de SO solicitou duas aulas sobre alguns comandos básicos e avançados dos sistemas operacionais Windows e Linux para serem ministradas nas turmas do $2^{\circ}$ ano do turno da manhã e da tarde. Em razão disso, foram elaboradas atividades específicas para cumprir o conteúdo programático.

Estando ciente dos conteúdos a serem trabalhados inicialmente, foi elaborado o plano de aula, sendo que cada discente deveria criar seu próprio plano e ministrá-lo em sala de aula. Devido este motivo, os conteúdos foram subdivididos em aulas específicas, para que assim cada discente pudesse criar seu plano de aula individualmente, como também ministrar a regência de seu plano e desta forma tomar as suas decisões como docente e ser avaliado sistematicamente pelo professor. 
Por meio dessa prática proporcionada pelo Estágio Supervisionado I foi possível para os discentes ter contato com o âmbito escolar e a vivência de ser um professor, fortalecendo seus pontos positivos e analisando seus limites na docência, experiência esta que fez cada discente refletir sobre a regência de sua aula, seu comportamento e atitudes em sala de aula, seu timbre de voz, sua postura de autoridade na mediação professor-educando-conteúdo-programas computacionais.

As experiências e os conhecimentos adquiridos durante a regência foram algo singular para cada discente, pois cada um vivenciou e aprendeu algo novo, seja pelos seus acertos ou erros. Como parâmetro para avaliar a atuação dos professores em formação em sala de aula, o professor da disciplina de $\mathrm{SO}$ analisou os discentes por meio de um Barema adaptado de Concurso Público para professor de nível técnico.

O resultado do Barema era apresentado aos discentes logo ao final de cada aula, no qual o professor de SO comentava cada aspecto importante que foi observado por ele durante a aula, dando assim o feedback imediato para cada integrante da equipe, informando todos os pontos positivos que foram percebidos, como também, orientando e sugerindo melhorias ao ver um ponto negativo na atuação dos discentes durante a regência da aula.

Como exemplo de algumas sugestões de melhorias citadas pelo professor da disciplina de SO que nos acompanhou durante as regências das aulas em sua disciplina foram: ter mais cuidado ao redigir um plano de aula, pois se deve levar em consideração todo o passo a passo que deve ser seguido para que ao final seja alcançado o objetivo da aula, incluindo o material necessário para a realização da mesma e tentar evitar vícios de linguagem enquanto está sendo ministrada uma aula.

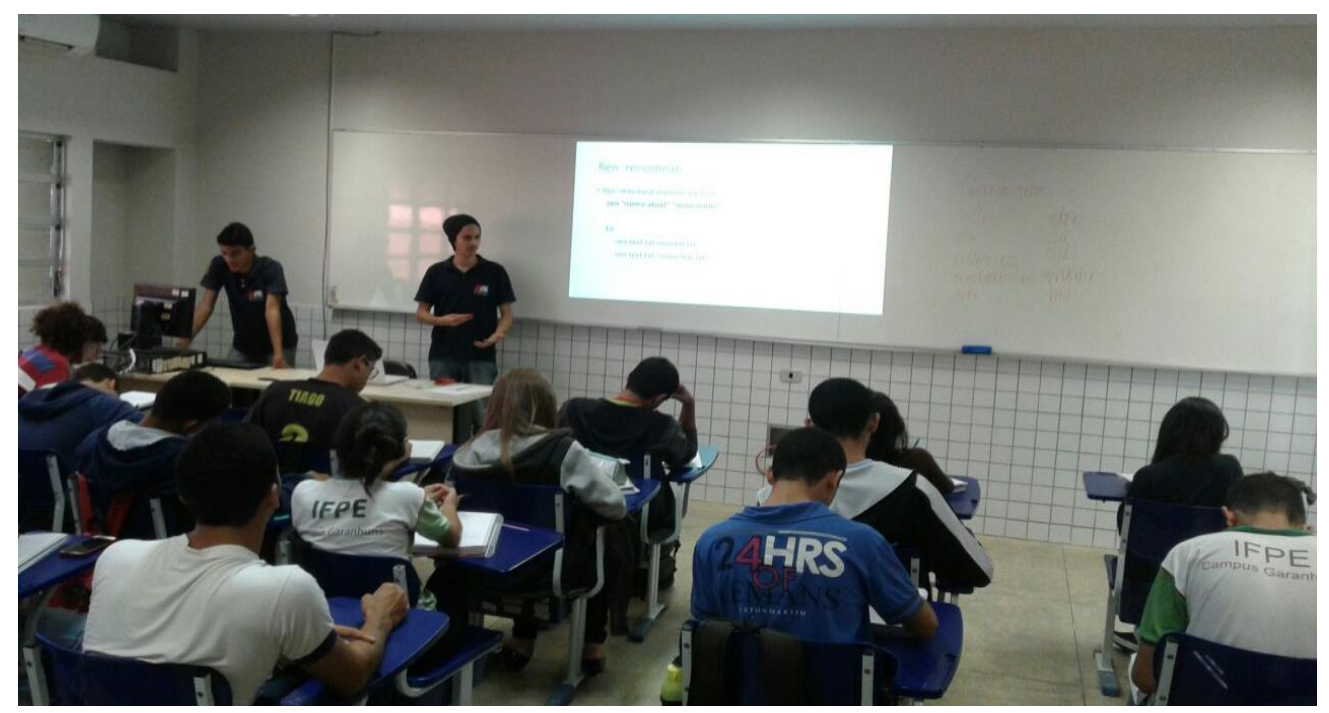

Figura 2. Aula da dimensão de Ensino sobre Comandos (Cmd) Windows.

Algo importante a ser mencionado foi o fato de que a fim de estimular os alunos na realização das atividades propostas na regência, o professor de $\mathrm{SO}$ resolveu premiar os educandos que resolvessem corretamente as atividades ao final das aulas, por meio de uma pontuação a ser aplicada nas atividades recorrentes da disciplina. Tal proposta provocou a turma a se concentrar na aula, participando e tornando a aula ainda mais atrativa e dinâmica, sendo possível ver nitidamente o interesse e o foco dos educandos em aprender durante toda a explicação dos estagiários. 
VI Congresso Brasileiro de Informática na Educação (CBIE 2017)

Anais dos Workshops do VI Congresso Brasileiro de Informática na Educação (WCBIE 2017)

\subsection{Extensão}

$\mathrm{Na}$ Extensão, as atividades foram divididas em duas, a primeira consistiu por uma sequência de aulas de reforço, com a duração de 17 horas no total, tendo como proposta a resolução de problemas, oriunda do planejamento do docente responsável pelas disciplinas de Algoritmos e LPOOED. A segunda atividade foi uma palestra com a duração de uma hora, intitulada "A Importância da T.I. Verde nas empresas".

As aulas de reforço ocorreram uma vez por semana, no turno da manhã. Neste período houve aulas teóricas e práticas ao longo do projeto, em que as duas primeiras aulas tiveram o caráter mais voltado para a teoria, pois nessas aulas foram lecionados conteúdos de programação na linguagem Java, mais especificamente, tipos primitivos e manipulação de dados.

As demais aulas de reforço deram continuidade aos conteúdos programáticos, mas de forma colaborativa, com o coordenador do curso de Informática do IFPE. Grande parte do foco do reforço era a resolução de listas de exercícios, entregues aos educandos nas aulas e levadas ao contra turno, nas aulas de reforço, das disciplinas de Algoritmos e LPOOED, podendo participar do reforço e sanar suas dúvidas ou dificuldades, também aqueles educandos que tinham horário disponível.

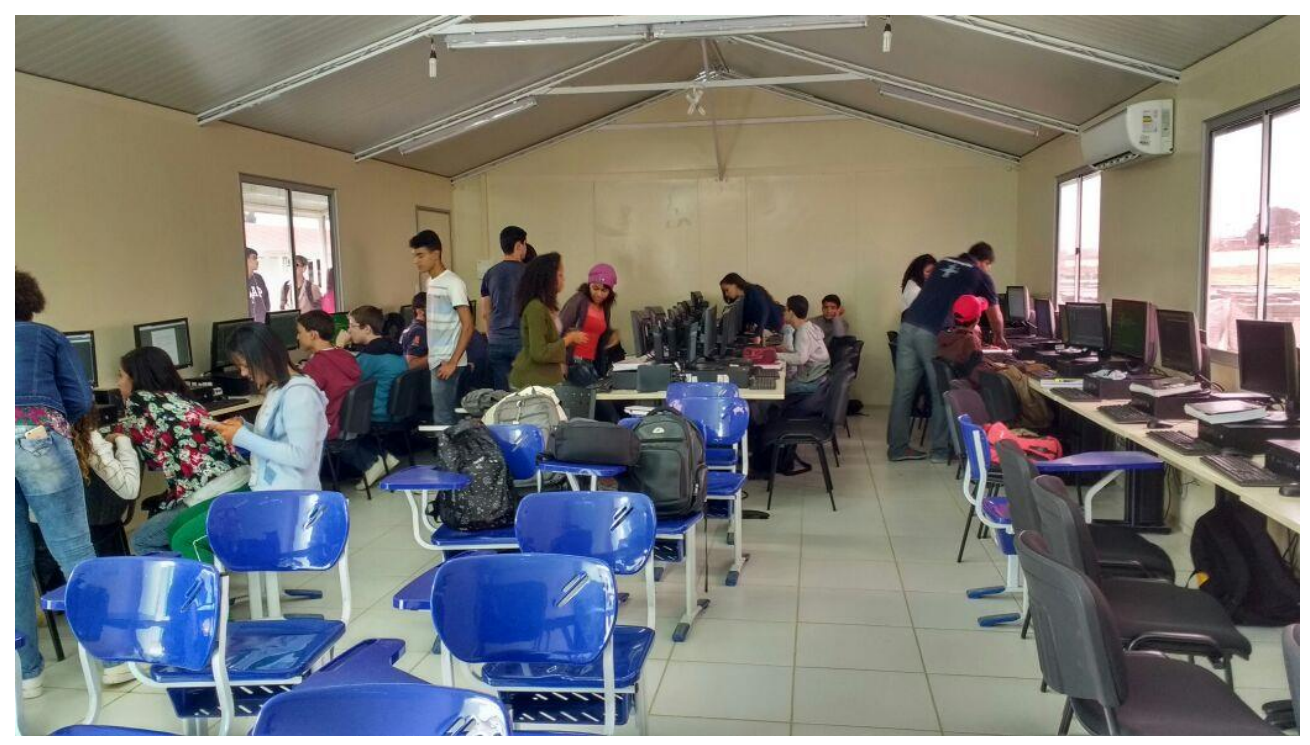

Figura 3. Auxílio na resolução das listas de exercício na aula de reforço.

Como pode ser visto na Figura 3, ao longo do projeto de Extensão vários estudantes, de diferentes turmas, participaram do reforço com o objetivo de aprender algo novo ou solucionar problemas de uma lista de exercícios de forma integrada e colaborativa, muitas vezes com novas formas de solucioná-los. E assim, como no Ensino, foi necessário realizar um planejamento e um estudo dos conteúdos que seriam abordados, mas com a diferença que teríamos mais liberdade para trabalhar, pois as aulas de reforço tinham uma característica mais dinâmica, os estagiários sempre estavam interagindo diretamente com um educando em prol de ajudá-lo a compreender algo que, muitas vezes, tinha uma dificuldade de aprendizagem.

Por último, ainda na dimensão da Extensão, a palestra abordando a temática TI Verde apresentada pelos discentes como mostra a Figura 4, objetivou proporcionar aos presentes o conhecimento das consequências do uso desenfreado das atuais tecnologias 
VI Congresso Brasileiro de Informática na Educação (CBIE 2017)

Anais dos Workshops do VI Congresso Brasileiro de Informática na Educação (WCBIE 2017)

e as atitudes que estão sendo executadas por empresas para amenizar os impactos ao meio ambiente, em decorrência dos avanços tecnológicos.

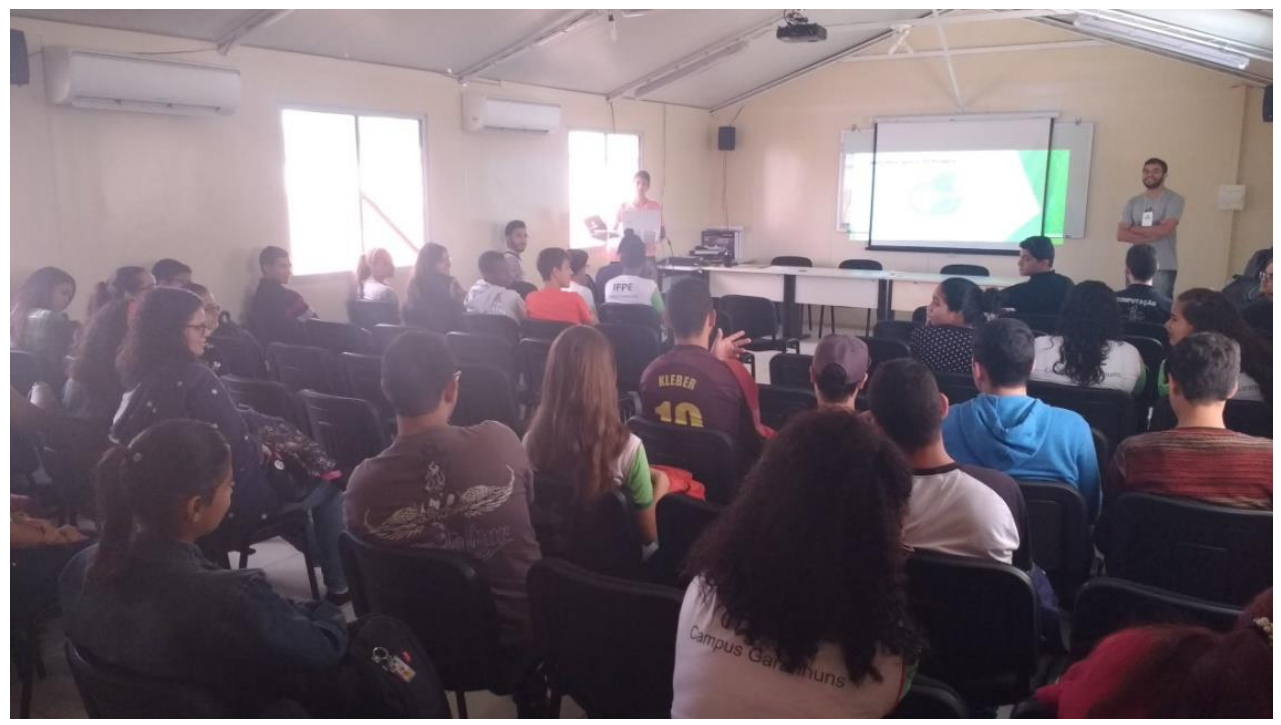

Figura 4. Palestra sobre TI Verde.

Ao final da palestra era esperado que os ouvintes refletissem sobre o tema e compreendessem a importância do uso da TI Verde em qualquer meio em que a tecnologia estivesse inserida.

\subsection{Constatações}

O produto das atividades realizadas nos projetos de Ensino e Extensão foram positivas quanto a docência, ao ponto de ultrapassar nossas expectativas, dando ênfase na dimensão de Ensino. Toda experiência adquirida pelos discentes que atuaram como professores em uma sala de aula foi uma oportunidade única de auto avaliar seus métodos e sua conduta como professor, como também em ser avaliado pelo professor da disciplina por meio do Barema.

Baseado em uma conversa durante a última aula na disciplina de $\mathrm{SO}$, a atuação em sala de aula foi considerada exemplar segundo os dados apresentados pelos educandos, que gostaram bastante das aulas, considerando-as dinâmicas, elogiando também a forma como trabalhamos com o professor da disciplina, aplicando atividades que contribuíram para elevar suas notas na disciplina.

O relato do professor de SO junto aos comentários dos educandos a respeito de nosso desempenho nas regências das aulas ministradas foi bastante gratificante, por meio desse feedback nós podemos melhorar nossa metodologia a ser utilizada em sala de aula, assim como nossa atuação no papel de professor, corrigindo os pontos fracos que foram descobertos durante a realização do projeto e aprimorando os pontos fortes que foram destacados pelo professor de SO.

Já no projeto de Extensão, os resultados obtidos foram satisfatórios, visto que conseguimos dar auxílio a vários educandos de diferentes turmas e ajudá-los a solucionar algum problema ou dificuldade que eles tinham quando foram recebidos nas aulas de reforço. 


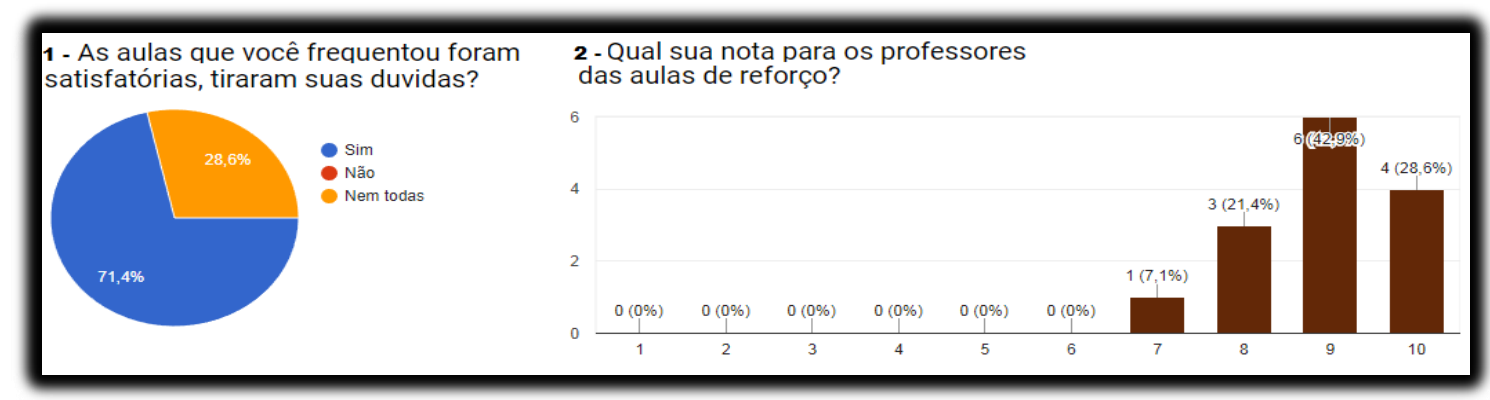

Figura 5. Gráfico de duas questões aplicadas no questionário de Extensão.

$\mathrm{Na}$ imagem da Figura 5 percebem-se os resultados de duas questões de um questionário que foi aplicado na última aula do reforço, onde na questão de número 1 demonstra o nível de satisfação dos alunos que participaram das aulas de reforço, que com um percentual de $71,4 \%$ de alunos satisfeitos com nossas aulas podemos notar que ainda precisamos nos aperfeiçoar mais e buscar novos métodos que permitam aprimorar nossa aulas.

Já a questão de número 2 da Figura 5 apresenta a nota com que os alunos nos avaliaram como professores, onde os resultados foram positivos, mas refletem que ainda falta algo a ser melhorado algo em nosso papel como professor. E vale frisar, que nem todos os educandos que participaram do reforço responderam a este questionário.

Os dados obtidos no questionário e os relatos dos estudantes que participaram do reforço demonstraram como foi efetiva a nossa intervenção na Instituição, de forma que se teve a liberdade de trabalhar os conteúdos sugeridos pelos professores do IFPE a nossa maneira, fazendo uso dos recursos disponíveis e de todo o aprendizado que obtivemos ao longo do Curso de Licenciatura em Computação. Deste modo, o Estágio cumpriu sua função prática, dinâmica, profissional, produtora, de troca se serviços e de possibilidades de abertura para mudanças, com os conhecimentos obtidos em prol de disseminar o ensino de programação e a assistência a qualquer educando que tivesse alguma dificuldade ou quisesse aprender ainda mais sobre os conteúdos que foram apresentados, através das aulas de reforço.

\section{Considerações finais}

A educação contemporânea se destaca pela necessidade de uma forma de ensino baseada na flexibilidade e na cooperação, para suprir as demandas dos mais variados educandos. Essa demanda exige do professor habilidade para lidar com os inúmeros desafios diários, no âmbito escolar. Habilidade esta que deriva da experiência adquirida ao longo de sua jornada como educador, iniciando muitas vezes na comunidade, mas adquirindo o nível profissional ao longo do curso de Licenciatura em Computação e de forma específica em Estágio Supervisionado.

Baseado nas informações apresentadas no decorrer deste relato, é perceptível a suma importância do Estágio Supervisionado na formação do futuro docente, visto que proporciona ao estagiário o contato direto com a rotina de desafios de um professor, oferecendo-o um enorme amadurecimento em relação às dificuldades, atitudes e decisões de um profissional da educação. Embasado nessas informações, concluímos que a experiência proporcionada pelo Estágio Supervisionado colaborou para a formação das características docentes necessárias para atender as necessidades do âmbito escolar, principalmente o desenvolvimento do caráter responsável, e criativo em 
VI Congresso Brasileiro de Informática na Educação (CBIE 2017)

Anais dos Workshops do VI Congresso Brasileiro de Informática na Educação (WCBIE 2017)

situações adversas, essencial a um professor.

\section{Referências}

Kulcsar, Rosa (2012). O estágio supervisionado como atividade integradora. In: Fazenda, Ivani Catarina Arantes [etall]; Piconez, Stela C. Bertholo (Coord.). A prática de ensino e o estágio supervisionado. Campinas-SP: Papirus.

Rosário, Maria. (2011). "A influência da mídia em crianças de 7 a 10 anos". In: http://tcconline.utp.br/wp-content/uploads/2012/06/A-INFLUENCIA-DA-MIDIAEM-CRIANCAS-DE-7-A-10-ANOS.pdf, Curitiba. Acesso em Março de 2017.

Moran, J. (2003). "Mudar a forma de ensinar e aprender com tecnologias: transformar as aulas em pesquisa e comunicação presencial-virtual". In: http://www.irrodl.org/content/v2.1/downes.pdf. Acesso em Abril de 2017.

Pimenta, S. G.; Lima, M. S. L (2011). Estágio e docência. São Paulo: Cortez.

Barema (2017). Adaptação do barema de Concurso Público conforme o Edital No 30 de 08 de abril de 2014, MEC, SEPT, IFE.

Scaico, P. D., Henrique, M. S., Cunha, F. O. M., \& de Alencar, Y. M. (2012). "Um Relato de Experiências de Estagiários da Licenciatura em Computação com o Ensino de Computação para Crianças". Renote, 10(3). 